\title{
Comparative Study on Cloud Parameter Estimation Among GOSAT/CAI, MODIS, CALIPSO/CALIOP and Landsat-8/OLI with Laser Radar: Lidar as Truth Data
}

\author{
Kohei Arai ${ }^{1}$ \\ ${ }^{1}$ Graduate School of Science and Engineering \\ Saga University \\ Saga City, Japan \\ Masanori Sakashita ${ }^{1}$ \\ ${ }^{1}$ Graduate School of Science and Engineering \\ Saga University \\ Saga City, Japan \\ Hiroshi Okumura $^{1}$ \\ ${ }^{1}$ Graduate School of Science and Engineering \\ Saga University \\ Saga City, Japan
}

\author{
Shuji Kawakami ${ }^{2}$ \\ ${ }^{2}$ Japan Aeronautical Exploration Agency \\ JAXA \\ Ibaraki, Japan \\ Kei Shiomi ${ }^{2}$ \\ ${ }^{2}$ Japan Aeronautical Exploration Agency \\ JAXA \\ Ibaraki, Japan
}

Hirofumi Ohyama ${ }^{3}$
${ }^{3}$ Nagoya University
Nagoya, Japan

order to detect cirrus clouds, $1.38 \mu \mathrm{m}$ of wavelength channel is adopted for Moderate resolution of Imaging Spectrometer: MODIS1 and Landsat-8 Operational Land Imager: OLI2, etc. Green house gasses Observation Satellite / Cloud and Aerosol Imager: GOSAT 3 /CAI (Cloud and Aerosol Imager) 4 is dedicated sensor for cloud and aerosol retrievals. Because that GOSAT 5/FTS (Fourier Transform Spectrometer 6) data is affected by clouds and aerosols, GOSAT/CAI is carried on the same platform of GOSAT satellite.

In order to check the capability of cirrus cloud detection, Light Detection and Ranging、Laser Imaging Detection and Ranging: Lidar data which allows measurement of back scattering ratio and depolarization ratio is used [17]-[29]. Preliminary study results of cirrus cloud detection are reported by authors [30]. The ground based Lidar is equipped at one of the GOSAT validation site which is situated at Saga University, Japan. Therefore, vertical profile of aerosol particles as well as cloud particles are detected which results in detection of aerosols and clouds including cirrus clouds. Vertical cloud structure can be retrieved with Cloud Aerosol Lidar and Infrared Pathfinder Satellite Observations:

\footnotetext{
${ }^{1} \mathrm{http}: / /$ modis.gsfc.nasa.gov/

${ }^{2}$ http://landsat.usgs.gov/landsat8.php

${ }^{3}$ http://www.gosat.nies.go.jp/

${ }^{4} \mathrm{http} / / /$ www.gosat.nies.go.jp/eng/gosat/page2.htm

${ }^{5}$ GOSAT carries FTS and CAI as mission instruments. FTS allows column

$\mathrm{CO}_{2}$ and $\mathrm{CH}_{4}$ estimations while $\mathrm{CAI}$ allows cloud and aerosol parameter estimations, respectively

${ }^{6}$ https://en.wikipedia.org/wiki/Fourier_transform_infrared_spectroscopy
} 
CALIPSO/CALIOP ${ }^{7}$ data. Therefore, detected cirrus clouds can be validated with CALIPSO/CALIOP data. In this paper, comparative study on cloud parameter estimation among GOSAT/CAI, MODIS, CALIPSO/CALIOP and Landsat8/OLI is carried out using Lidar as a truth data. Optical depth, size distribution, as well as cirrus type of clouds are cloud parameters. Although MODIS and Landsat-8/OLI have such channel, the other mission instruments, CAI and CALIPSO/CALIOP do not have such channel. As a truth data of cloud parameter, the ground based Lidar is used in this comparative study. From the Lidar, backscattered echo signal and depolarization coefficient are obtained as a function of altitude. Therefore, cloud type, vertical profile can be derived from the Lidar data. CALIPSO/CALIOP is satellite based Lidar which allows observation of clouds from space. Although the directions of laser light emissions between CALIPSO/CALIOP and the ground based Lidar are different, their principles are same. Therefore, it is expected that CALIPSO/CALIOP data derived cloud parameters are similar to the ground based Lidar data derived cloud parameters.

In the next section, the proposed method for evaluation of cirrus detection accuracy of GOSAT/CAI, CALIPSO/CALIOP, MODIS and Landsat-8/OLI is described followed by experiments which includes method and procedure as well as the obtained experimental results. Finally, conclusion and some discussion are described.

\section{RESEARCH BACKGROUND}

Using spaceborne based FTS, column $\mathrm{CO}_{2}$ and $\mathrm{CH}_{4}$ in the atmosphere can be estimated. In the estimation of these atmospheric continuants, clouds and aerosols are influencing factors for estimation. Therefore, clouds and aerosol parameters, effective particle size distribution, optical thickness has to be clarified. In order to eliminate such FTS data which are suffered from clouds and aerosols have to be identified and cloud and aerosol masks have to be created. Using the mask pattern, non-confidential FTS data is removed from the estimation of $\mathrm{CO}_{2}$ and $\mathrm{CH}_{4}$. Fig.1 (a) shows the FTS spectrum acquired on May 192014 (Clear sky condition) while Fig. 1 (b) shows that acquired on November 192014 (Cloudy condition, in particular, cirrus clouds). Fig.2 (a) shows the sky view camera image which acquired on May 19 2014 (Clear sky condition) while Fig.2 (b) shows that acquired on November 192014 (Cirrus cloud condition). It is obvious that the FTS spectrum which is suffered from cirrus clouds has influence due to cirrus clouds. Thus the retrieved column $\mathrm{CO}_{2}$ and $\mathrm{CH}_{4}$ of November 192014 has estimation error. Therefore, cirrus cloud detection is highly required for column $\mathrm{CO}_{2}$ and $\mathrm{CH}_{4}$ estimation with FTS. FTS has four spectral bands (Wave number of the bands range from 700 to $13200 \mathrm{~cm}^{-1}$ which consists of Band 4: 700-1800 $\mathrm{cm}^{-1}$, Band 3: 4800-5200 $\mathrm{cm}^{-1}$, Band 2: $5800-6400 \mathrm{~cm}^{-1}$, Band 1: 12900-13200 $\mathrm{cm}^{-1}$ )

${ }^{7}$ The Cloud-Aerosol Lidar with Orthogonal Polarization (CALIOP) onboard the Cloud-Aerosol Lidar and Infrared Pathfinder Satellite Observations (CALIPSO) satellite http://www.icare.univ-

lille1.fr/drupal/CALIPSO/CALIOP

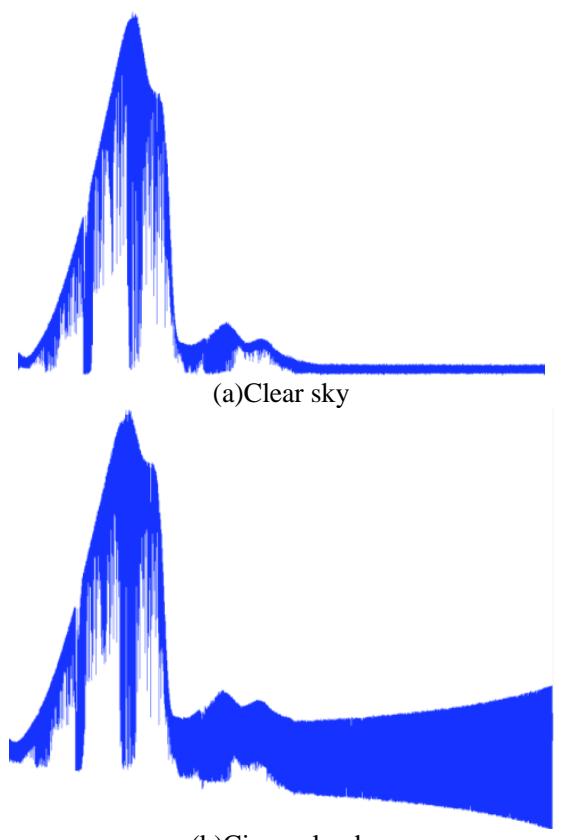

(b)Cirrus clouds

Fig. 1. Effect of cirrus clouds on retrievals of $\mathrm{XCO} 2, \mathrm{XCH} 4$ with FTS spectrum Wave number rages from 700 to $13200 \mathrm{~cm}-1$ (Band $4: 700-1800 \mathrm{~cm}$ 1, Band 3: 4800-5200 cm-1, Band 2: 5800-6400 cm-1, Band 1: 12900-13200 cm-1)
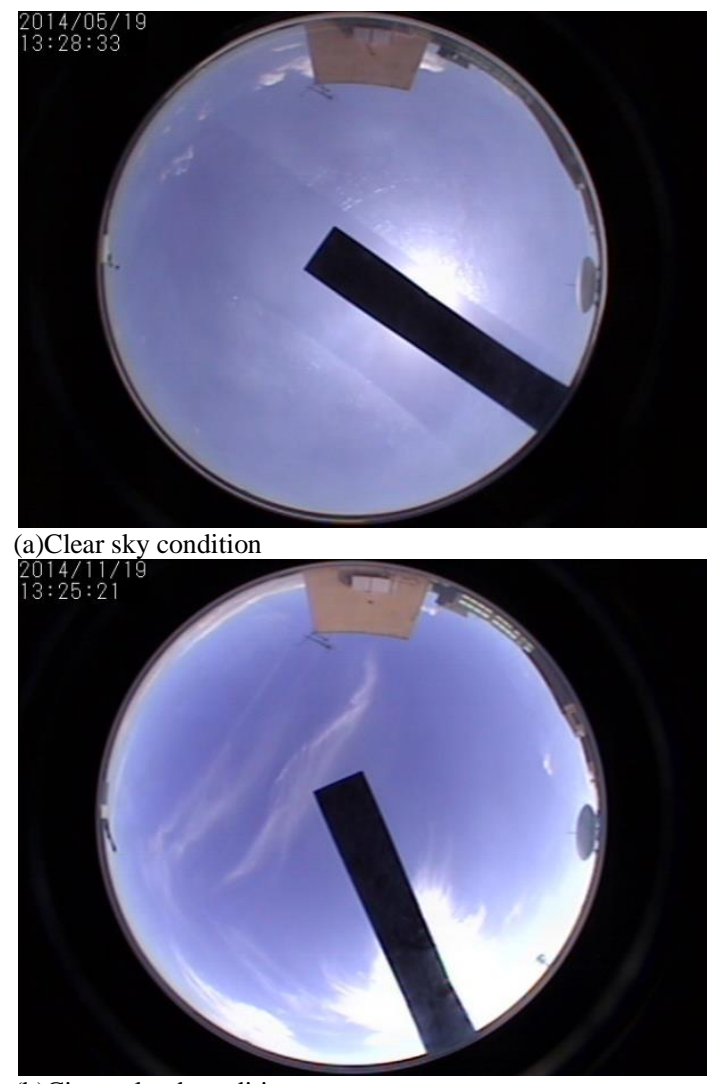

(b)Cirrus cloud condition

Fig. 2. Sky view camera images which are acquired on May 192014 (Clear sky condition) and on November 192014 (Cirrus cloud condition) 


\section{METHOD AND PROCEDURE}

\section{A. Lidar as Truth Data of Clouds}

There are $\mathrm{TCCON}^{8}$ validation sites in the world. One of these is Saga University site in Japan. The location and outlook is shown in Fig.3.

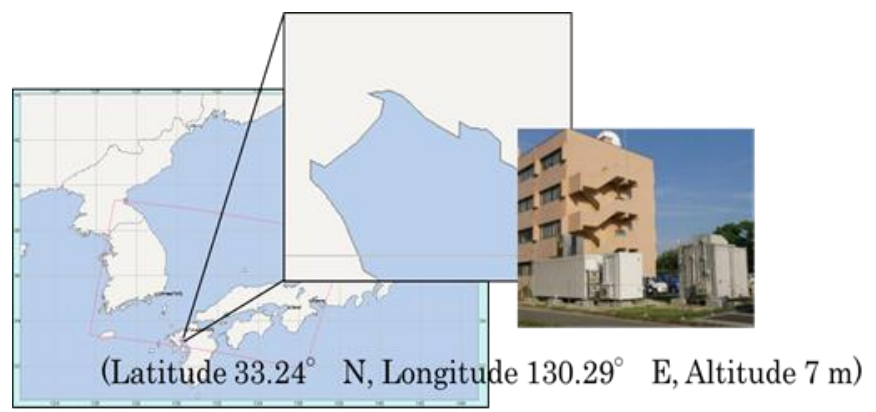

Fig. 3. Saga University TCCON site for GOSAT validation

\section{B. Lidar Data Derived Backscatterin Ratio and Depolarization Ratio}

Examples of the Lidar data derived backscattering ratio and depolarization ratio are shown in Fig.4. Backscattering ratio shows the back scattering strength from aerosol and cloud particles while depolarization ratio shows degree of spherical of the particulates.

Fig.4 (a) to (i) shows the lidar data derived backscattering ratio and depolarization ratio which are acquired on April 23, May 9, May 11, September 14, November 17, December 27 in 2014 and on January 20, March 25, June 29 in 2015, respectively. There are aerosol and cloud particles in the lower layer (boundary layer in troposphere) on April 232014 while it seems that there is cirrus clouds at around $12.5 \mathrm{~km}$, there are thin aerosol and cloud particles in the lower layer though. This is same thing for the lidar derived backscattering and depolarization ratios of May 11 2014. There seems to be cirrus cloud at around $12 \mathrm{~km}$, there are thin aerosol and cloud particles in the lower layer though. There are cirrus clouds at around $11.5 \mathrm{~km}$ on September 14 2014. On the other hand, it seems that there are non-spherical aerosol and cloud particles at around $1.5 \mathrm{~km}$ for the case of November 172014. Meanwhile, there are cirrus clouds at around $8 \mathrm{~km}$ for the case of December 272014.

There are low layer clouds at around $1 \mathrm{~km}$ for the case of January 202015 while comparatively clear sky condition is confirmed on March 25 2015. On the other hand, there are cirrus clouds at around $7 \mathrm{~km}$ for the case of June 292015.
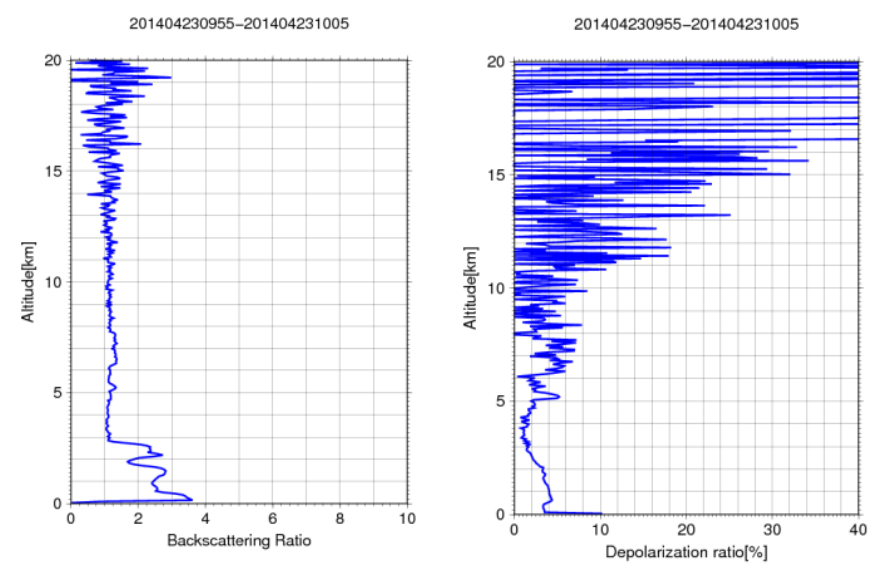

(a) $2014 / 04 / 23$
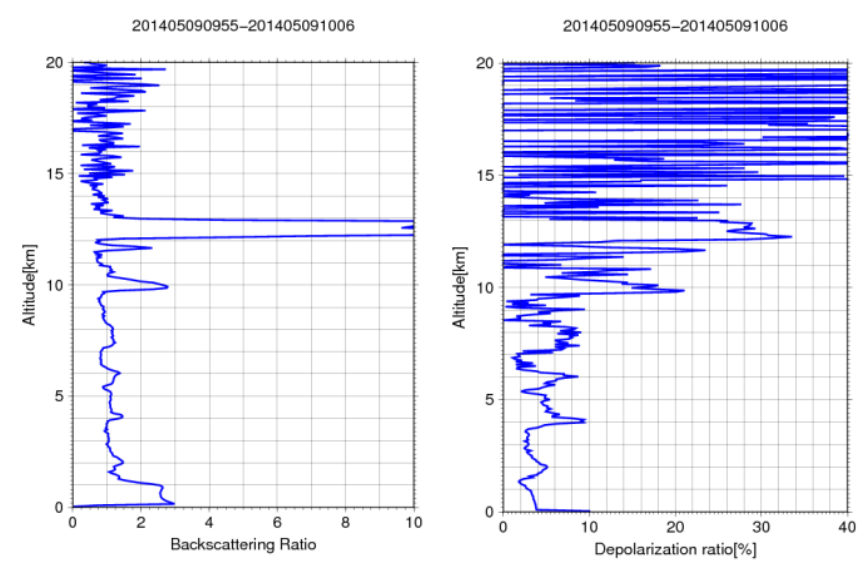

(b) $2014 / 05 / 09$
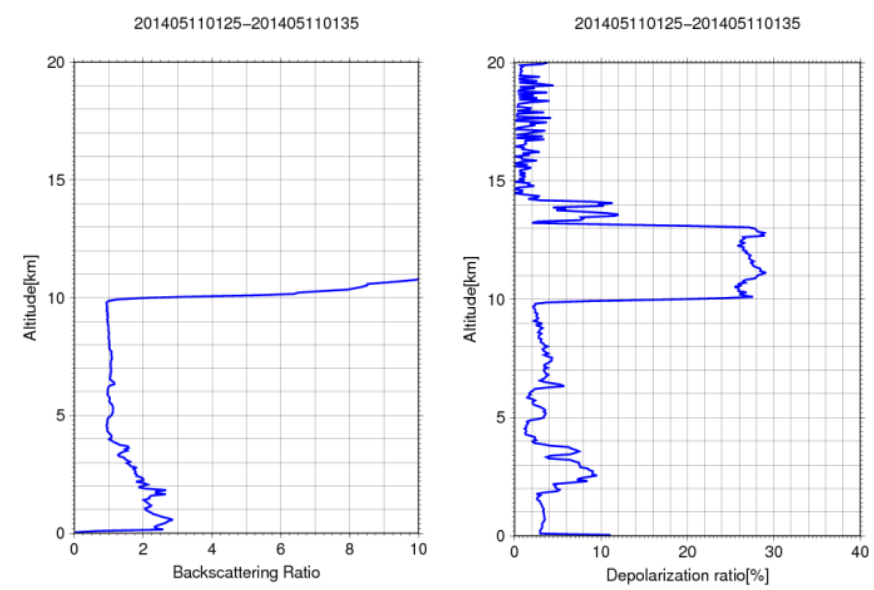

(c) $2014 / 05 / 11$

\footnotetext{
${ }^{8}$ The Total Carbon Column Observing Network (TCCON)
} 

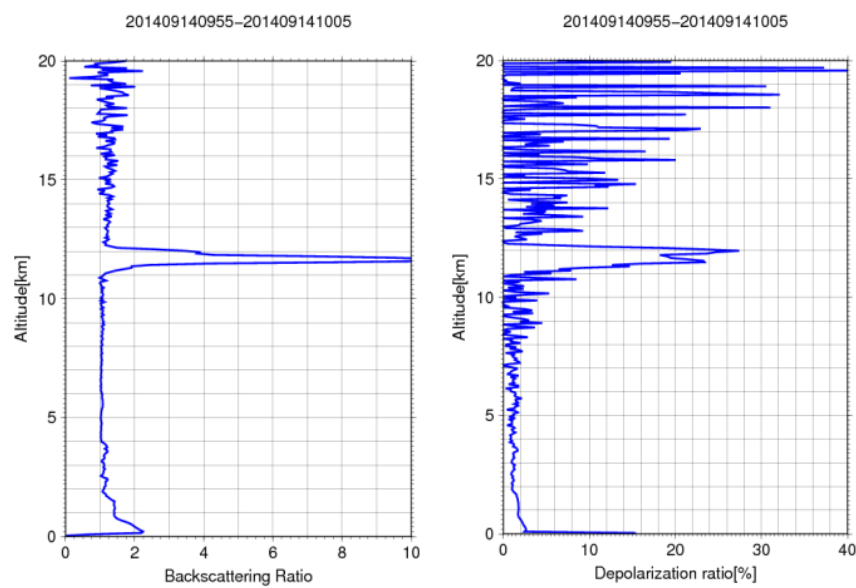

(d)2014/09/14
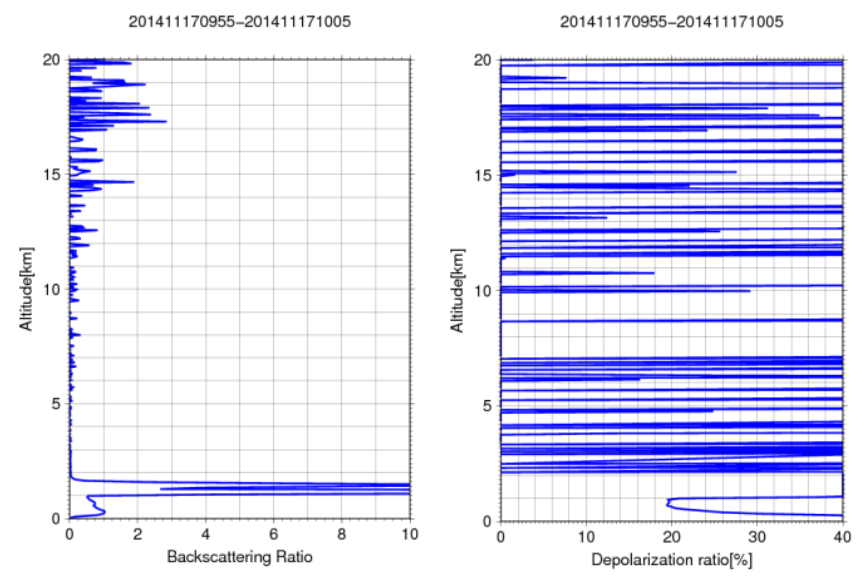

(e)2014/11/17
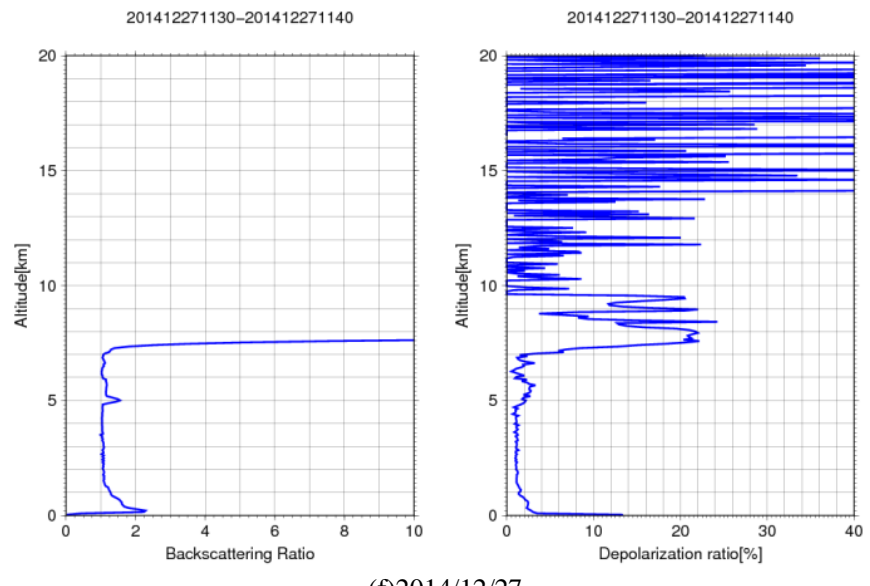

(f) $2014 / 12 / 27$
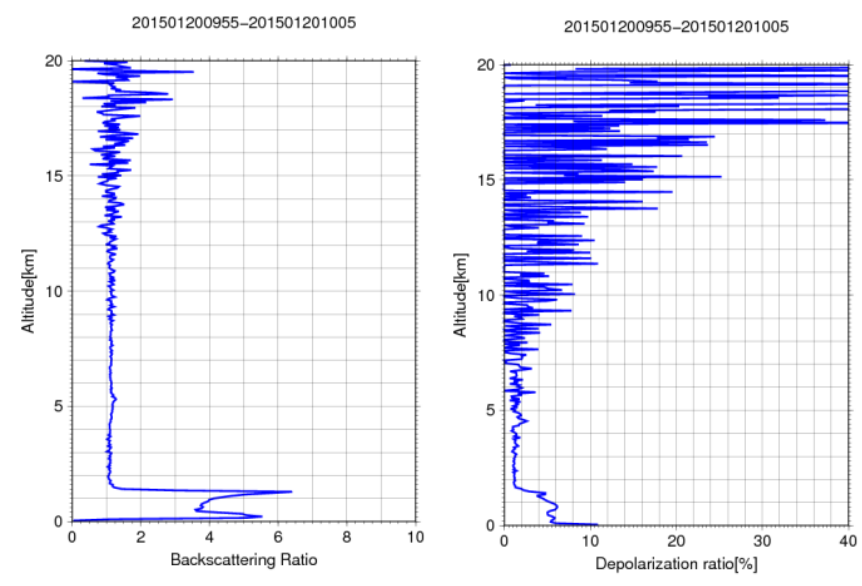

(g)2015/01/20
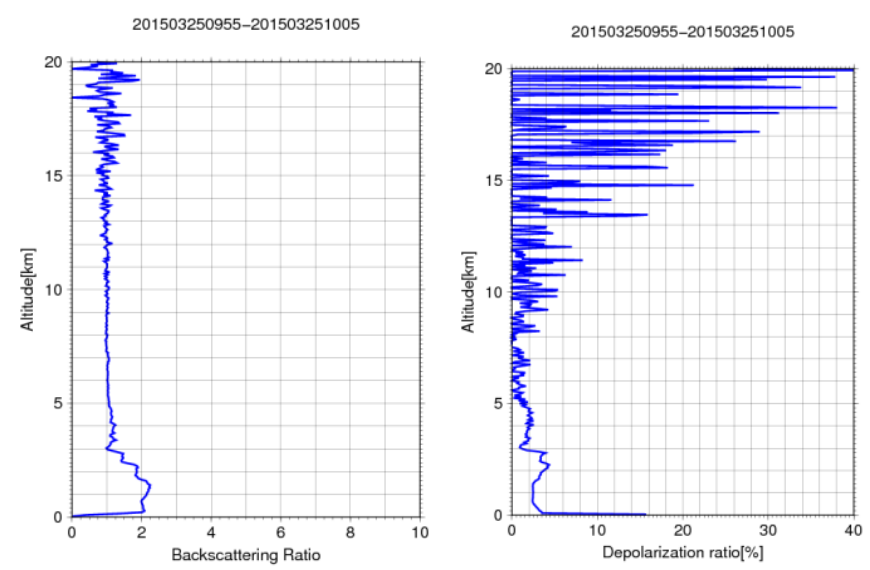

(h) $2015 / 03 / 25$
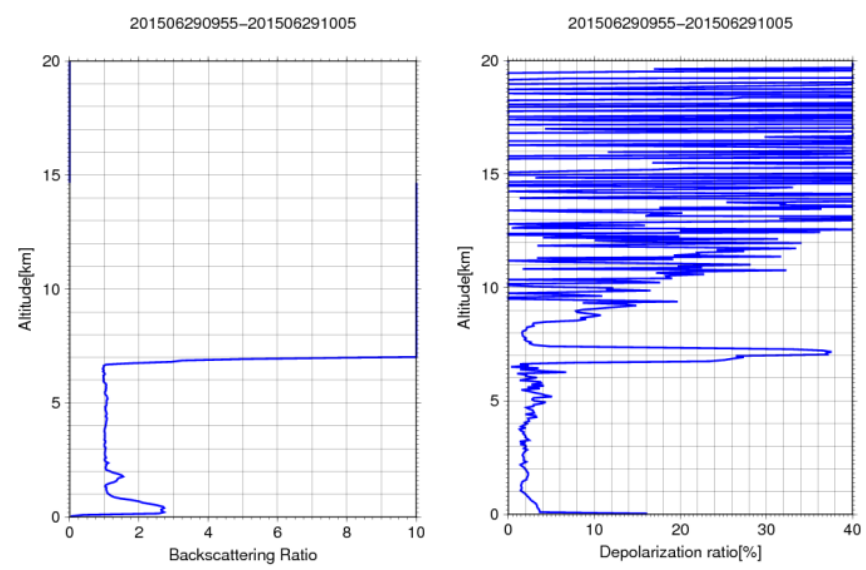

(i) $2015 / 06 / 29$

Fig. 4. Examples of lidar data derived backscattering ratio and depolarization ratio 


\section{Match-up Data Between the Ground Based Lidar Data} and the Cloud Sensor Onboard Satellites

GOSAT/CAI data are acquired for 173 days within 518 days from April 12014 to August 312015 (Revisit cycle of the GOSAT satellite is 3 days). Within 173 days, Lidar data are acquired for 48 days (Acquisition ratio of Lidar data to the total available days is just $33.01 \%$ ). Cirrus clouds are observed for 11 days out of 48 days. Meanwhile, cirrus clouds are detected with CAI for just 8 days out of 11 days. On the other hand, cloud free situations are found with CAI for 18 days out of 37 days which is confirmed with Lidar data. During from April 12014 to August 31 2015, the Lidar data is acquired for 96 times ${ }^{9}$ because the data is obtained in conjunction of GOSAT satellite observation of the Saga University TCCON site. Due to the fact that the Lidar data is acquired at the different time of the GOSAT satellite over pass time, 46 of match-up data are acquired between GOSAT/CAI and the Lidar data. Meanwhile, data acquisition time between MODIS data onboard Aqua satellite and the Lidar data is almost same. Therefore, 96 of match-up data are acquired between the Aqua/MODIS and the Lidar data. On the other hand, just 7 match-up data between Landsat-8/OLI and the Lidar are acquired while 7 match-up data between CALIPSO/CALIOP and the Lidar are acquired, respectively. Examples of the CALIPSO/CALIOP satellite track are shown in Fig.5.
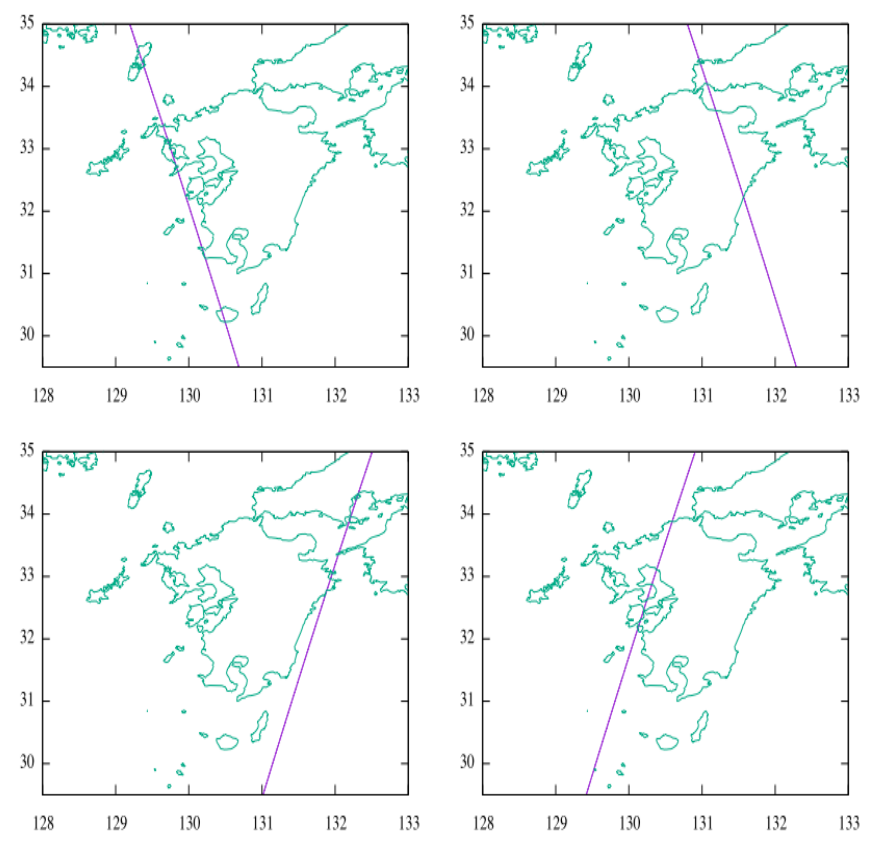

Fig. 5. Examples of the CALIPSO/CALIOP satellite track

Through a comparison between Fig.3 and Fig.5, it is truly rare to get match-up data between CALIPSO/CALIOP and the Lidar data (In these examples, only the satellite track which is shown in the bottom right is match-up to the ground based Lidar site).

\footnotetext{
${ }^{9}$ Lidar data are acquired in day and night time a day. Meanwhile, there are two observation chances on ascending and descending orbits a day. Therefore, twice many match-up data is acquired as match-up days
}

\section{EXPERIMENTS}

\section{A. Landsat-8/OLI}

There are 7 match-up data between the Lidar and Landsad8/OLI images. Fig.6 shows the match-up Landsat-8/OLI images. Color composite is assigned for red color to Band 5, for green color to Band 9, and for blue color to Band 6, respectively. Therefore, green colored pixels show existing of cirrus cloud because Band $9(1.38 \mu \mathrm{m})$ is dedicated spectrum channel for cirrus cloud detection.

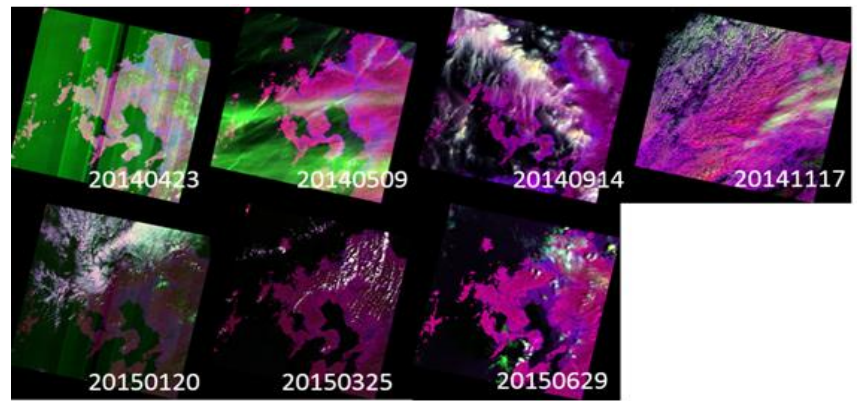

Fig. 6. Match-up data of Landsat-8/OLI imagery data with the Lidar data acquisition

Although Landsat-8/OLI data show the existing cirrus clouds, the Lidar data show no existing of such cirrus cloud at all. Cirrus clouds are used to be existed at around 5 to $15 \mathrm{~km}$ depending on latitude and season. There is no such evidence at the altitude in the Lidar data. Clearly, there are some evidences of the existing of cirrus clouds in the Lidar data. Also, Landsat-8/OLI shows the same existing of cirrus clouds. Therefore, both Landsat-8/OLI and Lidar show good coincidence.

TABLE I. COMPARISON BETWEEN LANDSAT-8/OLI AND LIDER DERIVED CIRRUS

\begin{tabular}{|l|l|l|l|}
\hline & \multicolumn{2}{|l|}{ Lidar } & Landsat-8/OLI \\
\hline YYMMDD & Backscattering & Depolarization & Cirrus \\
\hline 140423 & Not exist & $5 \% \sim 35 \%$ & No \\
\hline 140509 & $12 \mathrm{~km}$ & $5 \% \sim 35 \%$ & Yes \\
\hline 140914 & $11 \mathrm{~km}$ & $5 \% \sim 35 \%$ & Yes \\
\hline 141117 & Not exist & $>35 \%$ & Yes \\
\hline 150120 & Not exist & $5 \% \sim 35 \%$ & No \\
\hline 150325 & Not exist & $<35 \%$ & No \\
\hline 150629 & $8 \mathrm{~km}$ & $<35 \%$ & No \\
\hline
\end{tabular}

Table 1 shows the summarized results of the experiments through comparison between Landsat-8/OLI and Lidar derived cirrus clouds. As a result through experiments, five coincidences are confirmed between Landsat-8/OLI and Lidar derived cirrus clouds out of seven cases. Therefore, approximately $71 \%$ of cirrus cloud detection accuracy is confirmed for Landsat-8/OLI data.

\section{B. Aqua/MODIS}

96 days Aqua/MODIS data are match upped with GOSAT/FTS data. Cirrus clouds are detected with Aqua/MODIS data for 72 days out of 96 days. MODIS has $1.38 \mu \mathrm{m}$ (cirrus detectable channel) and $660 \mathrm{~nm}$ channel for removal of land surface influence in the cirrus clouds detection. Therefore, good cirrus cloud detection accuracy is expected. 
MODIS cloud products (MYD03: Cirrus data and MYD06: Longitude / Latitude data) used for analysis. Fig.7 is an example of MYD03 of cirrus reflectance flag data. Black portions show cirrus clouds. On the other hands, Fig.7 shows Lidar data, Sky view camera imagery data, and MODIS imagery data of December 27 2014. Fig.8 (a) shows existence of the cirrus clouds and also MODIS imagery data of Fig.8 (b) shows existence of the cirrus clouds.

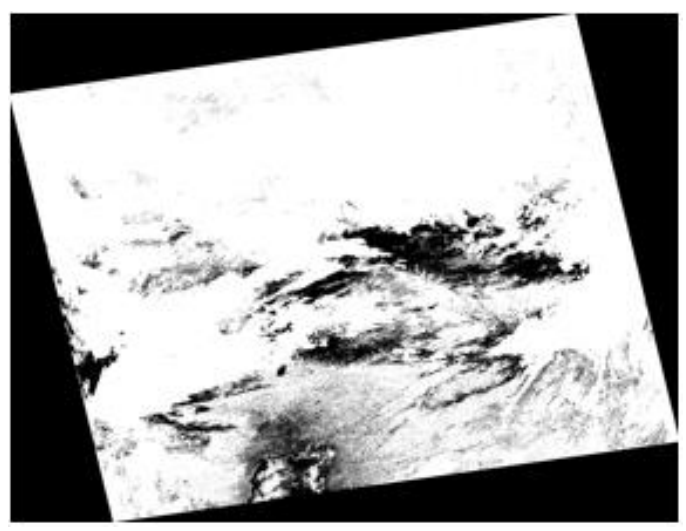

Fig. 7. Example of MYD03 of cirrus reflectance flag data
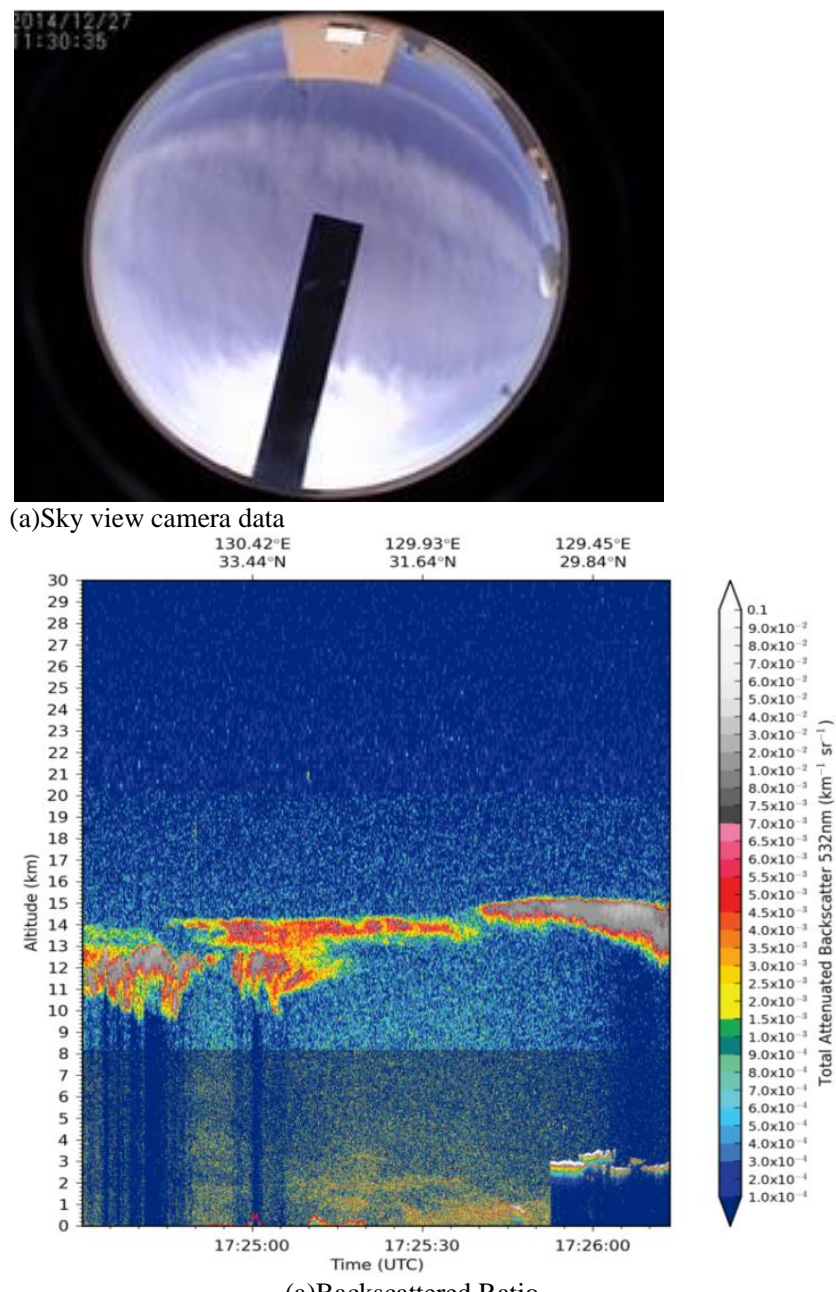

(a)Backscattered Ratio

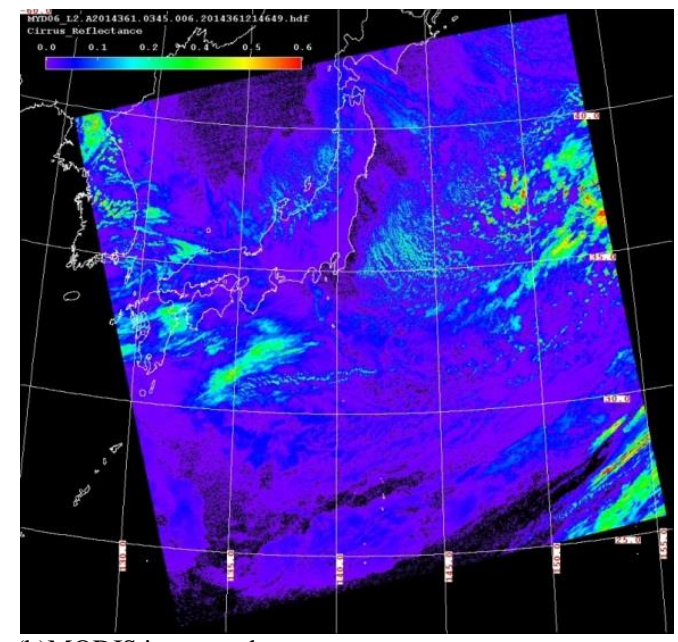

(b)MODIS imagery data

Fig. 8. Example of MODIS derived cirrus clouds

\section{CALIPSO/CALIOP}

The CALIPSO/CALIOP data of the orbit for the bottom right in the Fig.5 are used for analysis. It is found the match up data of CALIPSO/CALIOP data (7 days out of 173 days). One of examples of CLIPSO/CALIOP image data is shown in Fig.9. Around the center of these images, the Saga University TCCON site is situated. It is clearly seen that there are cirrus clouds at around the altitude of 10-14 km above sea level.

On the other hand, Fig.10 shows MODIS Band 31 imagery data which acquired almost same time on that day. Both CALIPSO/CALIOP and Lidar data (Fig.4 (c)) are coincident. This is same thing for the other 6 days. Therefore, the match upped CALIPSO/CALIOP data show $100 \%$ perfect cirrus cloud detection accuracy.

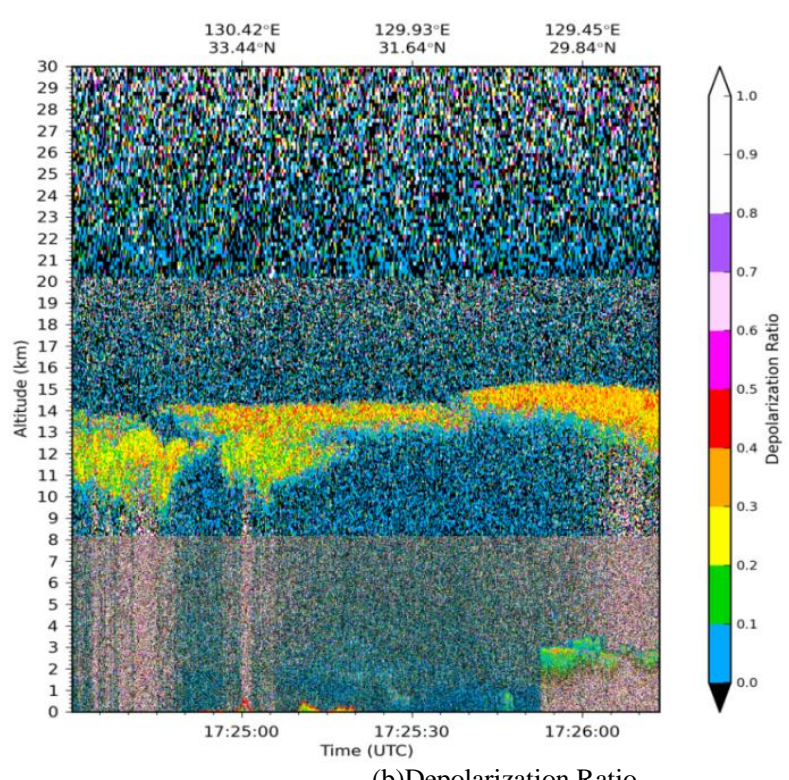

(b)Depolarization Ratio

Fig. 9. One of the examples of CALIPSO/CALIOP image data 


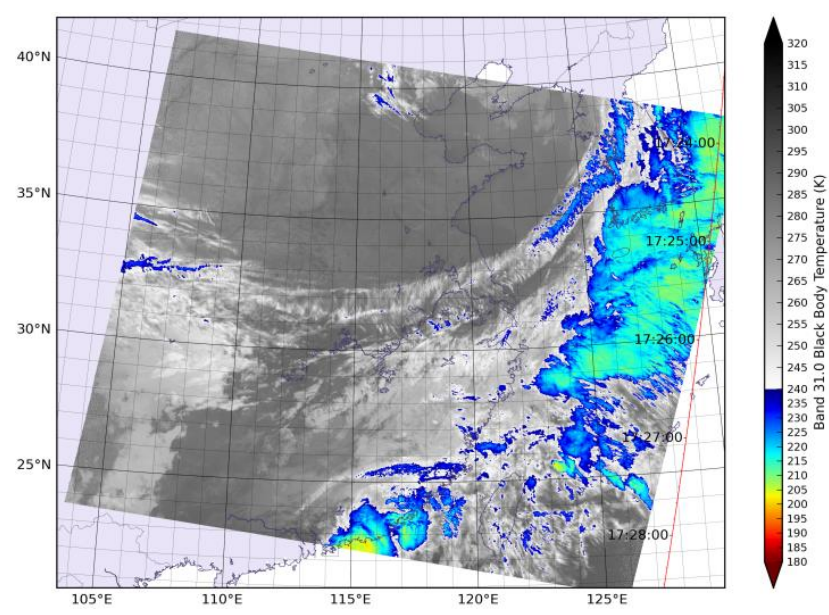

Fig. 10. MODIS Band 31 of brightness temperature at that time on that day (Lidar data of back scattering ratio and depolarization ratio at the time on May 112014 is shown in Fig.4 (c))

\section{GOSAT/CAI}

The pixels of which the ratio of Band 4 (1.60um) and Band $3(0.87 \mathrm{um})$ is greater than 0.8 are identified as cirrus contaminated pixels. Band 4 is for detecting clouds while Band 3 is for removing surface reflectance influence. One of the examples of cirrus cloud detection is shown in Fig.11. The match up ratio is around $26.6 \%$ (46 days out of 173 days) while cirrus detection accuracy is approximately 52\% (24 days out of 46 days).

The results of the comparative study are summarized in the Table 2.

TABLE II. SUMMARIZED RESULTS OF THE COMPARATIVE STUDY

\begin{tabular}{|l|l|l|l|l|}
\hline & CALISPO & Landsat8 & MODIS & GOSAT \\
\hline Number of match up data & 7 & 7 & 96 & 46 \\
\hline $\begin{array}{l}\text { Number of coincide cirrus } \\
\text { detected data }\end{array}$ & 7 & 5 & 75 & 24 \\
\hline Cirrus cloud detection accuracy & $100 \%$ & $71 \%$ & $75 \%$ & $52 \%$ \\
\hline
\end{tabular}

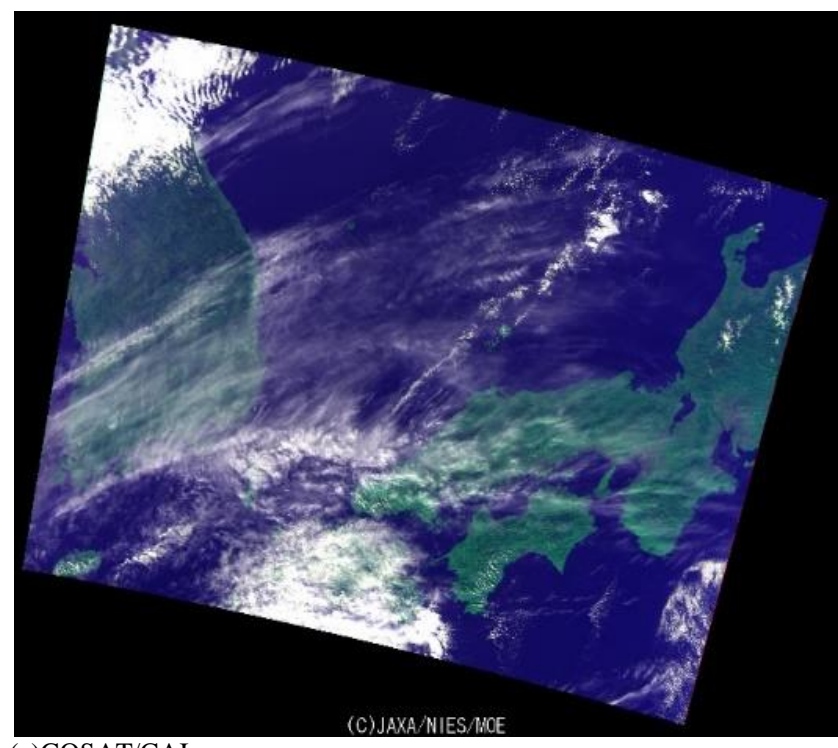

(a)GOSAT/CAI

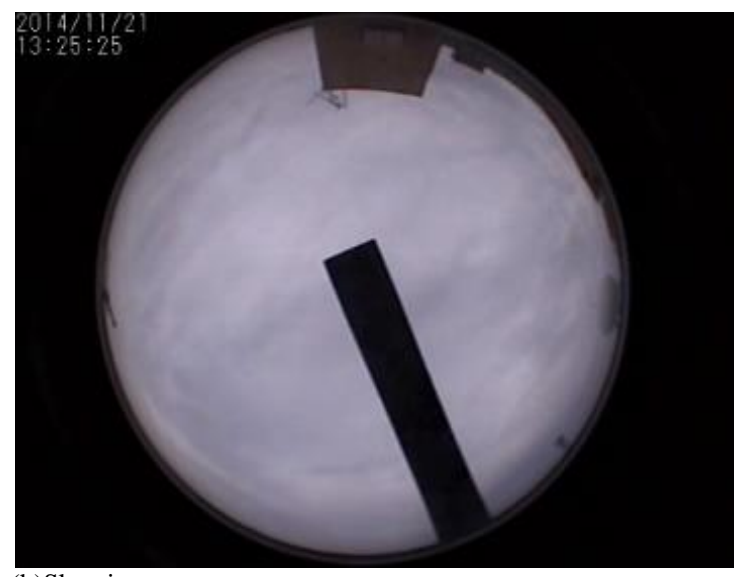

(b)Sky view camera

Fig. 11. Example of GOSAT/CAI detected cirrus clouds

\section{RECOMMENDABLE CIRRUS CLOUD DETECTION}

CALIPSO/CALIOP shows the best cirrus cloud detection accuracy (100\%) followed by Aqua/MODIS, Landsat-8/OLI and GOSAT/CAI. CALIPSO/CALIOP is dedicated to cloud detection and has Lidar as mission instrument. Therefore, it is obvious that cirrus detection accuracy is excellent. Meanwhile, swath width of the CALIPSO/CALIOP is not so wide that entire globe coverage cannot be achieved within a day. On the other hand, swath width of Aqua/MODIS ensures entire globe coverage within a day for cirrus cloud detection accuracy is not so high though. Therefore, complementary use of Aqua/MODIS and CALIPSO/CALIOP would be recommendable combination for cirrus cloud distribution of entire globe within a day.

\section{CONCLUSION AND FUTURE WORKS}

A comparative study on cloud parameter estimation among GOSAT/CAI, MODIS, CALIPSO/CALIOP and Landsat8/OLI is carried out using Laser Radar: Lidar as a truth data. Optical depth, size distribution, as well as cirrus type of clouds are cloud parameters. In particular, cirrus cloud detection is tough issue. $1.38 \mu \mathrm{m}$ channel is required for its detection. Although MODIS and Landsat-8/OLI have such channel, the other mission instruments, CAI and CALIPSO/CALIOP do not have such channel. As a truth data of cloud parameter, ground based Lidar is used in this comparative study. From the Lidar, backscattered echo signal and depolarization coefficient are obtained as a function of altitude. Therefore, cloud type, vertical profile can be derived from the Lidar data. CALIPSO/CALIOP is satellite based Lidar which allows observation of clouds from space. Although the directions of laser light emissions between CALIPSO/CALIOP and the ground based Lidar are different, their principles are same. Therefore, it is expected that CALIPSO/CALIOP data derived cloud parameters are similar to the ground based Lidar data derived cloud parameters. The experimental results show the aforementioned facts and are useful for improvement of cloud parameter estimation accuracy with several sensor data combinations.

Cirrus cloud detection accuracy of GOSAT/CAI and Landsat-8/OLI is evaluated with a ground based Laser Radar: Lidar data and sky view camera data. Also, the evaluation 
results are confirmed with CALIPSO/CALIOP data together with a topographic representation of vertical profile of cloud structure. Furthermore, origin of cirrus clouds is estimated with forward trajectory analysis. The results show that GOSAT/CAI derived cirrus clouds is not accurately enough due to missing of cirrus cloud detection spectral channel while Landsat- 8 derived cirrus cloud.

In order to create cirrus cloud flag for GOSAT/FTS, it is recommendable to use GOSAT/FTS data derived spectrum. As shown in Fig.1, the spectrum which is suffered from cirrus cloud has specific feature in the spectrum (Relatively large variance in the greater wave number region is observed for cirrus cloud contaminated FTS data). This cirrus cloud flag creation is one of future research works. Also, the complementary use of Aqua/MODIS and CALIPSO/CALIOP would be one of future research works for cirrus cloud distribution of entire globe within a day.

Further study is required for assess and evaluate the recommendable method for cirrus cloud detection as well as flagging to the acquired GOSAT/FTS data.

\section{ACKNOWLEDGEMENTS}

Authors would like to thank Dr. Osamu Uchino and Dr. Isamu Morino of National Institute of Environmental Science as well as Dr. Toshiharu Izumi for providing of their lidar derived backscattering ratio and depolarization ratio as well as valuable comments and suggestions.

\section{REFERENCES}

[1] Remote Sensing Society of Japan Edt. Kohei Arai, et al., Remote Sensing -An Introductory Textbook-, Maruzen Planet Publishing Co. Ltd., Chapter 9 Radiometric Correction and Cloud Detection, 155-172, p.301, ISBN978-4-86345-185-8, 2013.

[2] Kohei Arai, A Merged Dataset for Obtaining Cloud Free IR Data and a Cloud Cover Estimation within a Pixel for SST Retrieval, Asian-Pacific Remote Sensing Journal, Vol.4, No.2, pp.121-127, Jan.1992

[3] Kohei Arai, Yasunori Terayama, Yoko Ueda, Masao Moriyama, Cloud Coverage Estimation Within a Pixel by Means of Category decomposition, Journal of the Journal of Japan Society of Photogrammetry and Remote Sensing,, Vol.31, No.5, pp.4-10, Oct.1992.

[4] Kohei Arai, Tasuya Kawaguchi, Adjacency Effect Taking Into Account Layered Clouds Based on Monte Carlo Method, Journal of Remote Sensing Society of Japan, Vol.21, No.2, pp.179-185, (2001).

[5] Kohei Arai, Tatsuya Kawaguchi, Adjucency Effect of Layered Clouds taking Into Account Phase Function of Cloud Particles and MultiLayered Plane Parallel Atmosphere Based on Monte Carlo Method, Journal of Japan Society of Photogrammetry and Remote Sensing, Vol.40, No.6, 2001.

[6] Kohei Arai, Adjacency effect of layered clouds estimated with MonteCarlo simulation, Advances in Space Research, Vol.29, No.19, 18071812, 2002.

[7] Kohei.Arai, Merged dataset with MOS-1/VTIR and NOAA/AVHRR enhancing cloud detectability, Proc. of the 28th COSPAR Congress, MA4-3.1, 1-8, 1990.

[8] Kohei.Arai, Estimation of partial cloud coverage within a pixel, Proc. of the Pre-ISY International Symposium, 99-106, 1991.

[9] Kohei.Arai, Sea surface temperature estimation taking into account partial cloud within a pixel, Proc. of the ISY conference on Earth and Space Information Systems, 10/13, 1992.

[10] Kohei.Arai, Y.Ueda and Y.Terayama, Comparative study on estimation of partial cloud coverage within a pixel -Proposed adaptive least square method with constraints- Proc. of the European ISY Conference, 305/310, 1992.
[11] Kohei.Arai, SST estimation of the pixels partially contaminated with cloud, Proc. of the Asian-Pacific ISY (International Space Year) Conference, 1992.

[12] Kohei Arai, Adjacency effect due to a box type of 3D clouds estimated with Monte Carlo simulation considering the phase function of cloud particles, Abstracts of the 33rd COSPAR Scientific Assembly, A1.20061, Warsaw, Poland, July 16-23, (2000).

[13] Shin-ichi.Sobue, Kohei.Arai and N.Futamura, Development of a method of cloud detection in Japanese Earth observation satellites, Proceedings of the ISTS (International Space Science and Technology Symposium), N-6, 2002-n-21,2002.

[14] Shin-ichi Sobua and Kohei Arai, Development of method for cloud detection in ASTER image data, Proc. of the 24th International Symposium on Space Technology and Science (ISTS), n-01, (2004)

[15] T. Sakai, O. Uchino, I. Morino, T. Nagai, S. Kawakami, H. Ohyama, A. Uchiyama, A. Yamazaki, K.Arai, H. Okumura, Y. Takubo, T. Kawasaki, T. Akaho, T. Shibata, T. Nagahama, Y. Yoshida, N. Kikuchi, B. Liley, V. Sharlock, J. Robinson, T. Yokota, Impact of aerosol and cirrus clouds on the GOSAT observed $\mathrm{CO} 2$ and $\mathrm{CH} 4$ inferred from ground based lidar, skyradiometer and FTS data at prioritized observation sites,(2013), Proceedings of the 9th International Workshop on Greenhouse Gas measurements from Space, IWGGMS-9, 2013

[16] Hiroshi.Okumura, Kohei Arai, Improvement of PM2.5 density distribution visualization system using ground-based sensor network and Mie Lidar, Proceedings of the Conference on Remote Sensing of Clouds and the Atmosphere, SPIE Remote Sensing, ERS 15-RS 104-50, 2015

[17] Osamu Uchino, Tetsu Sakai, Tomohiro Nagai, Masahisa Nakasato, Isamu Morino, Tatsuya Yokota, Tsuneo Matsunaga, Nobuo Sugimoto, Kohei Arai, Hiroshi Okumura, Development of transportable Lidar for validation of GOSAT satellite data products, Journal of Remote Sensing Society of Japan, 31, 4, 435-443, 2011

[18] O.Uchino, T.Sakai, T.Nagai, I.Morino, K.Arai, H.Okumura, S.Takubo, T.Kawasaki, Y.mano, T.Matsunaga, T.Yokota, On recent stratspheric aerosols observed by Lidar over Japan, Journal of Atmospheric Chemistry and Physics, 12, 11975-11984, 2012(doi:10.5194/acp-12, 11975-2012).

[19] Testu Sakai, Osamu Uchino, Isamu Morino, Tomohiro Nagai, Taiga Akaho, Kawasaki Tsuyoshi, Tetsu Sakai, Hiroshi Okumura, Kohei Arai, Akihiro Uchiyama, Akehiro Yamazaki, Tsuneo Matsunaga, Tatsuya Yokota, Vertical profile of volcanic prumes form Sakurajima volcano detected by Lidar and skyradiometer situated Saga and its optical property, Journal of Remote Sensing Society of Japan, 34, 3, 197-204, 2014

[20] H. Okumura, S.Takubo, T.Kawsaki, I.N.Abdulah, T.Sakai, T.Maki, K.Arai, Web based data acquisition and management system for GOSAT validation Lidar data analysis, Proceedings of the SPIE Vol.8537, Conference 8537: Image and Signal Processing for remote Sensing, Paper \#8537-43, system, 2012.

[21] T.Sakai, H. Okumura, T.Kawsaki, I.N.Abdulah, O.Uchino, I.Morino, T.Yokota, T.Nagai, T.Sakai, T.Maki, K.Arai, Observation of aerosol parameters at Saga using GOSAT product validation Lidar, Proceedings of the SPIE Vol.8526, Conference 8526: Lidar Remote Sensing for Environmental Monitoring XIII, SPIE Asia-Pacific Remote Sensing, Paper \#8295A-50,IP1, 2012.

[22] Hiroshi Okumura, Shoichiro Takubo, Takeru Kawasaki, Indra Nugraha Abdulah, Osamu Uchino, Isamu Morino, Tatsuya Yokota, Tomohiro Nagai, Tetu Sakai, Takashi Maki, Kohei Arai, Improvement of webbased data acquisition and management system for GOSAT validation Lidar data analysis(2013), SPIE Electronic Imaging Conference, 2013.

[23] Hiroshi Okumura, Kohei Arai, Observation of aerosol properties at Saga using GOSAT product validation LiDAR, Proceedings of the Conference on Image and Signal Processing fo Remote Sensing, SPIE \#ERS13-RS107-38, 2013

[24] T. Sakai, O. Uchino, I. Morino, T. Nagai, S. Kawakami, H. Ohyama, A. Uchiyama, A. Yamazaki, K.Arai, H. Okumura, Y. Takubo, T. Kawasaki, T. Akaho, T. Shibata, T. Nagahama, Y. Yoshida, N. Kikuchi, B. Liley, V. Sharlock, J. Robinson, T. Yokota, Impact of aerosol and cirrus clouds on the GOSAT observed $\mathrm{CO} 2$ and $\mathrm{CH} 4$ inferred from ground based lidar, skyradiometer and FTS data at prioritized observation sites,(2013), 
Proceedings of the 9th International Workshop on Greenhouse Gas measurements from Space, IWGGMS-9, 2013

[25] Shuji Kawakami, Hirofumi Ohyama, Kei Shiomi, T.Fukamachi, Kohei Arai, C.Taura, H.Okumura, Observations of carbon dioxide and methane column amounts measured by high resolution of FTIR at Saga in 20112012, Proceedings of the International Symposium on Remote Sensing, ISRS-TCCOC 2013.(2013)

[26] Osamu Uchino, T.Sakai, T.nagai, I.Morino, H.Ohyama, S.Kawakami, K.Shiomi, T Kawasaki, T.Akaho, H.Okumura, Kohei Arai, T.matsunaga, T.Yokota, Comparison of lower tropospheric ozone column observed by DIAL and GOSAT TANSO-FTS TIR, Proceedings of the AGU Fall Meeting 2013.(2013)

[27] I Morino, T Sakai, T.Nagai, A.Uchiyama, A.Yamazaki, S Kawakami, H.Ohyama, Kohei Arai, H.Okumura, T.Shibata, T.Nagahama, N.Kikuchi, Y.Yoshida, Ben Liley, Vannessa Sherlock, John Robinson, O. Uchino, T.Yokota, Impact of aerosols and cirrus on the GOSAT onboard $\mathrm{CO} 2$ and $\mathrm{CH} 4$ inferred from ground based Lidar, skyradiometer and FTS data at prioritized observation sites, Proceedings of the AGU Fall Meeting 2013.(2013)

[28] Hiroshi.Okumura, K.Arai, Development of PM2.5 density distribution visualization system using gournd-level sensor network and Mie-Lidar, Proceedings of the SPIE European Remote Sensing Coference, ERS 14RS107-97, 2014.

[29] Hiroshi.Okumura, Kohei Arai, Improvement of PM2.5 density distribution visualization system using ground-based sensor network and
Mie Lidar, Proceedings of the Conference on Remote Sensing of Clouds and the Atmosphere, SPIE Remote Sensing, ERS 15-RS 104-50, 2015

[30] Kohei Arai, Masanori Sakashita, Evaluation of cirrus cloud detection accuracy of GOSAT/CAI, and Landsat-8/OLI with Laser Radar: Lidar and confirmation with CALIPSO/CALIOP data, International Journal of Advanced Research on Artificial Intelligence, 5, 1, 14-21, 2015.

\section{AUTHORS PROFILE}

Kohei Arai, He received BS, MS and $\mathrm{PhD}$ degrees in 1972, 1974 and 1982, respectively. He was with The Institute for Industrial Science and Technology of the University of Tokyo from April 1974 to December 1978 also was with National Space Development Agency of Japan from January, 1979 to March, 1990. During from 1985 to 1987, he was with Canada Centre for Remote Sensing as a Post Doctoral Fellow of National Science and Engineering Research Council of Canada. He moved to Saga University as a Professor in Department of Information Science on April 1990. He was a councilor for the Aeronautics and Space related to the Technology Committee of the Ministry of Science and Technology during from 1998 to 2000. He was a councilor of Saga University for 2002 and 2003. He also was an executive councilor for the Remote Sensing Society of Japan for 2003 to 2005 . He is an Adjunct Professor of University of Arizona, USA since 1998. He also is Vice Chairman of the Commission "A" of ICSU/COSPAR since 2008. He wrote 34 books and published 520 journal papers. He is now Editor-in-Chief of IJACSA (International Journal of Advanced Computer Science and Applications) and IJISA (International Journal of Inteligent System and Applications). http://teagis.ip.is.saga-u.ac.jp/index.html 